\title{
Building Affordable Touchpad Tablets and Integrating it within Undergraduate Students' Curriculum
}

\author{
Mohamad Tabbara (Corresponding Author) \\ Higher Colleges of Technology, United Arab Emirates \\ E-mail: mtabbara@hct.ac.ae
}

Received: June 16, 2015 Accepted: June 27, 2015 Published: August 8, 2015

doi:10.5296/jet.v2i2.8132 URL: http://dx.doi.org/10.5296/jet.v2i2.8132

\begin{abstract}
This research paper will discuss the process and consequences of allowing undergraduate students to build their own touchpads and integrate it within their daily learning activities. The paper will try to capture the student's acceptance level toward the procedure and its anticipated academic results. The level of student's acceptance will be measured based on a group of statistical questions such as the amount of time and level of difficulties encountered during the assembly process. Moreover, the discussion will elaborate toward the opportunities that can be achieved in terms of students' learning mobility and overall enhancements of their educational performance. At this point, a group of survey questions will investigate the affiliation between allowing the student's to build their own touchpads and the fact of achieving better academic results. In this respect, a group of 39 students currently studying at the Higher Colleges of Technology (HCT), in Abu Dhabi Women's College (ADWC), will be asked to be part of a questionnaire to record their behaviour and overall impression in relation to the touchpad assembly and its usage.
\end{abstract}

Keywords: Touchpad assembly, Affordable touchpad building, Student's educational enhancements

\section{Introduction}

A learning environment that promotes the development of creativity, innovativeness and capability for self-directed lifelong learning in students will have a strong flavour of constructivist learning, rather than one of teacher-dominated declarative learning. Students will be active agents in the construction of their own knowledge, rather than passive recipients of that knowledge from teachers (Moyle, 2010).

The Higher Colleges of Technology (HCT) has more than 20,000 students attending 17 different campuses throughout the United Arab Emirates (U.A.E) where they study over 40 different work-relevant, career programmes in Engineering Technology, Computer \& 
Information Science (CIS), Health Sciences, Business, Applied Communications and Education. The CIS department in the HCT has more than 5000 enrolled students pursuing many different computer specialties including Software Engineering, Multimedia and Animation, Security/Forensics and Business Solutions. All the CIS students will need to undergo common Information Technology basic courses to give them the sufficient infrastructure to be able to successfully pursue their studies in the computer field. In this respect, one of the basic IT courses that is commonly given to all the students is the course "Computer Hardware \& Software". It's a 3 credit introductory course that covers basic computer hardware and software theory and practice. In the past 10 years, all students were obliged at the end of the hardware section of the course to assemble a desktop Personal Computer (PC). Upon the completion of the task, each desktop computer will be formatted and tested for functionality. Eventually all desktops are disassembled and stored back to be used by the next batch of students. At this point, all the labs in the CIS department are equipped with the latest laptops, and all students usually purchase their own laptops to study and perform their exercises. As a result, students were loosing interest in the process of assembling desktop PC's for the simple reason that is the lack of investing their practical work into applied usage. In addition to that, the fact that all PC's need to be disassembled at the end of the semester and never be used for conducting any kind of projects was upsetting and demotivating the students. Moreover, most the students in the CIS department have the latest mobile technologies (smart phones, touchpads, laptops) available under their disposal, this fact made the students less interested in a relatively old technology such as PC assembly and usage.

At this point the head of the CIS departments came up with an initiative to buy a relatively inexpensive and unbranded 7 inches touchpad tablet's parts, and give the chance for all incoming students to assemble it. The touchpad parts cost on an average of "30 US" dollars for one complete device. All the parts were bought directly from E-FORTUNE Digital Manufactory Limited that is a factory in china that design and produces its own touchpad parts. In this respect, students assemble their touchpads and test it for functionality, and then the touchpad is cumulatively given to the class and they are asked to come up with a project or an idea that can benefit their college, educational achievements, or society.

The next sections will discuss the educational uses and utilizations of touchpad tablets in general within the HCT system. Moreover, a list of benefits in terms of projects conducted on the new assembled touchpads will be given to highlight the importance of the imitative. Section 3 will present the results of a group of surveys given to 39 CIS students whom previously assembled the touchpads and created a set of quality relative projects. In consequence to that, a statistical comparison will be conducted in order to benchmark the level/standards of student's projects who worked on the touchpads assembly in comparison to students who worked only on the PC's. Section 4 will present technical information on the touchpad tablets parts and assembly process. Section 5 will offer a detailed comparison in terms of specifications and prices between the new assembled touchpad and the branded ones. Concluding remarks will be presented at the end of the paper. 


\section{Tablets Usage within the HCT System:}

Over the past years, a number of studies have shown benefits from the use of technology in education. The role of technology in education is vital, and the question is no longer if technology enhances learning, but rather how do we improve our use of technology to enhance learning (Saxena, 2013).

In consequence to the rise of usage of mobile technology, many educational paradigms had to adapt to the rapid growth of hardware and software. In the last couple of years, technology in general and touchpads smart devices in specific became a focal point in the infrastructure of many educational institutes. Many students in the U.A.E and especially within the HCT system enter the CIS department with full previous experience on how to operate touchpads.

Multiple devices are available to and owned by students, which can complicate issues such as the design of training and provision of support. Although many students own mobile devices, ownership is not universal. Identifying specific student demographics that might relate to ownership trends is thus critical. It is also important to determine which devices are most helpful for academic use; mobile technologies afford new opportunities for learning, but their use does not guarantee that effective learning will take place (Baiyun \& Denoyelles, 2013).

HCT students start experimenting with touchpad tablets and smart phones on a relatively early age at home and at school. The HCT encourages all their students to own an apple iPad or any other smart device that can facilitate their studies and give an extra hand in their educational pursuing. The core idea behind using touchpad tablets in the HCT is to allow the device to act as a mobile educational console that can assist students in their educational research and testing. In this respect the touchpad tablet will be used in parallel to laptops as an assistive technology to enhance, practice and empower certain educational areas during the student's time of study in the HCT. Almost all departments including the CIS encourage their students to use smart tablets touchpads to conduct projects, test software and apply practical skills. At this point, two major issues were observed and recorded in terms of students using the touchpad. The first issue lays in the over price factor of the touchpad devices. Branded devices such as Apple, Samsung, Acer, Asus and so many others are relatively expensive especially for college students. The second and most important issue lays in the fact that many students in the CIS departments feel obliged to purchase the touchpad device, but soon they will loose interest in using it for educational purposes. In other words, it will end up used as any other gaming console solely for entertainment including gaming and browsing the Internet.

At this point the management of the CIS department in the HCT came up with the idea of having the students work and assemble their own touchpad tablets. The management wanted the students to feel involved and have a sense of accomplishment in the device as they are building it. In opposite to the sense of ownership a sense of accomplishment will bind the students to the device and will allow them to see the touchpad as a learning tool rather than just an object they bought with their money. To place this theory into practise, the teaching outline of the course "Computer Hardware \& Software" was updated at the beginning of the fall semester 2014, and the assembled touchpad practise was integrated within the course 
learning objectives. During the course and in the first couple of weeks, students were asked to read about touchpad assembly and watch couple of in-house developed videos documenting the process. In consequence to that, faculty were practically demonstrating to the students the process of assembling touchpad and giving some basic electronic soldering practices. After that, students were given the proper tools and instruments in addition to all the touchpad tablets bits and pieces, and were asked to follow a detailed specified process to start the assembly practical. During a period of 6 hours divided across a week and half, the students needed to assemble their touchpads and test it for functionalities. During this process the students developed a strong sense of accomplishment, pride and achievement. The job of the faculty was at that point to invest in the students' work and capitalise on their realization. That was achieved by giving the students a group of projects that needed to be carried out on the newly created device. Moreover, the faculty allowed the students to brainstorm project ideas with their newly assembled touchpad devices in mind.

\subsection{Examples of projects already executed using the new Touchpad Tablets:}

The touchpad tablets assembly process started last year at the beginning of the fall semester 2014. The first batch of CIS students finished their training and started assembling touchpads in the month of January 2014. Since than around 350 students, in the CIS department system wide, were trained and successfully assembled their own devices. The touchpad assembly is being utilized in the CIS department in the following areas:

\subsubsection{Teaching practical hardware assembly:}

One of the main reasons behind the touchpad assembly initiative was the need to modernize the process of hardware assembly that was for the last 15 years depending solely on assembling desktop computers. Smart devices, touchpads and laptops in general are the devices that are heavily used by students in the HCT. Therefore it's only natural to bring these latest technologies into student's curriculum in the form of hardware assembly. The CIS department has around 5000 enrolled students all around HCT 17 campuses, and every student in their first year of enrolment has to take a compulsory introductory computer course "Computer Hardware \& Software". The course has introductory theory on computer systems and hardware/software identification. Moreover, students are required to put their theoretical knowledge in practice and assemble a computer system. In this respect, and during the preparation sessions on the assembly process the students are introduced to the names and functionality of each part of the touchpad. In addition to that, students are given induction sessions in basic knowledge on soldering electronics and handling wires properly. Eventually, a 40 minuets video demonstrating the process of assembling the touchpad will be played in the classroom. Students will be given between 4 to 6 hours spreading over the period of a week and a half to practice and assemble their own touchpad devices.

\subsubsection{Using the assembled touchpads in "Stop Motion" projects}

One of the most important factors that was observed after the first batch of students finished assembling their touchpads tablets, was the amount of pride the students showed in their achievement. Students were extremely excited about their touchpad tablets and wanted to 
showcase it to all their friends and family members. At this point, and during the spring semester, the same group of students who had worked on the touchpad in the fall semester decided to demonstrate their final multimedia project using their assembled touchpad. They wanted to showcase a project on Stop Motion animation. Stop Motion is an animation technique that uses frame-by-frame capturing while slowly incrementing object. In this respect a static object can be brought to live motion on screen. A group of 9 students each with her newly assembled touchpad worked on a common theme and divided the work among them. They downloaded on each touchpad a free software called "Stick Sketch" and they aligned the 16 touchpad in a matrix form of 4 by 4 . Each student was responsible to draw a stick-man animation on one or two touchpads that is made out of 104 frames that simulate a specific role in the overall theme. Each frame represents a specific place/time in the stickman journey. As a result, when the students run the stop motion animation all at the same time, the stick-man will be imitating the moving from one touchpad to the other in a coordinated manner that simulate the over all theme the students had in mind. The theme students used were "escaping from a closed room". The stick-man starts as a trapped character inside a sealed room in the first touchpad and pushes its way out through each touchpad through a set of coordinated moves and funny behaviour till the character eventually finds its way out to freedom in touchpad 16. The overall outcome and the total devotion students put in this project were outstanding.

\subsubsection{Using the assembled touchpads in Augmented Reality projects:}

A group of 11 students downloaded the free software LAYAR. That is an augmented reality application that allows user to project layers of data above a specific image or webpage. Students used Photoshop image processing software to create their basic images and the augmented layers. The project was designed toward the ministry of health in Abu Dhabi. The students designed cover boxes of medicines where the end-users need to look at it using their assembled touchpad running the LAYAR software. The touchpad uses its 2 Megapixel front camera to capture the image of the medicine box and virtually augment many other important information/layers into the touchpad front 7" screen. Eventually the end user will be looking at the actual medicine cover in addition to all the beneficiary augmented information such as expiry date, side effects, and proper medicine usage. Once again students who already worked on the touchpad assembly created the project, and they used their own devices all through the project planning, design and implementation.

\subsubsection{Using the assembled touchpads in business solution courses:}

This project was completely done by Dubai Men's College CIS students. The students took their assembled touchpads that is already labelled with the HCT logo and went to the mall of the emirates in order to sell the devices. 30 assembled touchpads were sold over the period of 2 days. All the profit made was donated to the UAE Red Crescent. Students during this project learned many essential skills in hardware assembly, business commerce and financial management. 
2.1.5 Using the assembled touchpads as a mean for research:

Year four undergraduate students in the CIS department in Abu Dhabi Women's College are working on the touchpad assembly process to optimise it and make it more accessible for a range of needed high school students. They hope that the process of optimising the assembly process will make it easier for students to build their own touchpads and therefore can use it in their educational activities. Students are looking into many options to bring the touchpad parts further less than 30 US dollar and are hoping to be able to cut off some of the accessories to bring the total amount of one touchpad to 19 dollars. A group of three students are currently preparing a written research paper on the issue and will use it as part of their last year graduation project at the end of fall semester 2015.

\section{Student's Feedback and Acceptance}

The touchpad assembly process started last academic year in the fall semester of 2014. It's a system wide process therefore all the 17 colleges within the HCT had the opportunity to give the assembly practice twice already for all their bachelors and diploma students. In Abu Dhabi colleges we have more than 120 students who already trained and practised on the touchpad assembly. At this point, a group of 39 students were surveyed in order to determine the level of usability, attachment, acceptance, academic improvement, and difficulty of the process. The survey was divided into two main categories. The first part focused on the level of students' experience in electronics, difficulties encountered, general acceptance, and most of the technical part of the touchpad assembly. The second part dealt with the level of student's attachment in terms of usability of the touchpad. Moreover, a set of students academic results were also compiled in an attempt to establish a positive correlation between students' enhanced academic performance and the fact of students using the new touchpad assembly. In this perspective, the final grades of a group of 12 students who took the course "2D 3D animation" last year were compared to the grades of 8 students who currently finished the same course but used their own touchpads to perform the final project. Students responded to the survey anonymously. All the 39 students in the surveyed group answered to the survey. The results of the survey were manually entered into Microsoft excel sheet and analyzed using statistical tools. Following is a summary of the survey results:

The majority of the students in the introductory course "Computer Hardware \& Software" have no previous involvement at all in electronics. According to Figure 1. 77\% out of the student's surveyed respondent that they have no experience at all in electronics, while only $13 \%$ stated that they have an average experience, and the rest $10 \%$ have minor knowledge. This proves that in the later process of building the touchpads previous experience in electronics is not that important. At the same time, if we look at Figure 2, 97\% of all respondents expressed that they have not assembled any touchpad device or smart phone prior to coming to this course. The above two questions showed a majority of students who lack technical and electronic assembly knowledge, therefore in the process of building touchpads previous experience is not needed. On the other hand, according to Figure 3, 72\% of respondents showed either an extreme enthusiasm or a moderate with some concerns to the idea of assembling touchpads in their course. This shows a high motivational level and willingness to 
learn new computer hardware assembly skills. In the second part of the survey, the questions were directed toward the process of assembly and the students' level of acceptance. All participated students were given an introduction session on the assembly process and were obliged to view a documentary video explaining the step-by-step process of the touchpad assembly. Figure 5, shows that students' reaction to the level of difficulty of the induction session ranged between $56 \%$ who expressed moderate difficulty in understanding the videos and materials against $38 \%$ stating that it was extremely difficult. As a result, we can deduce that the majority of students had difficult time trying to understand the materials in its theoretical form. At the same time, according to Figure 6, 90\% of participants recorded that it took them around 6 hours to completely finish the practical part of assembling the touchpads. In fact, that was planned from the right beginning as students were given a week and a half (6 complete periods) to finish their work. At this point, in contrast to the $38 \%$ of students who expressed their difficulties in learning the assembly process in theory, figure 7 shows that only $8 \%$ stated that the actual practical assembly was difficult, whereas $90 \%$ of all participants expressed moderate level of difficulties in the technical assembly of the touchpads. This demonstrates that students were better in practical skills compared to the theoretical one. In fact, the most difficult part for all the students was the soldering part. Students as mentioned earlier have very minimum experience in electronics handling. Therefore when they reached the part where they have to solder the battery, Wi-Fi antenna and the touch panel display into the motherboard they were struggling. On the other hand, figure 9 shows that $97 \%$ of students expressed an extremely positive rating for the overall process of assembling the touchpad. This proves that the decisive majority actually enjoyed the process of building touchpads. The fact that the majority of the participants had their touchpad assembled and working properly made the experience for all students more rewarding. Students felt a sense of achievement and were very proud of their accomplishment. According to figure 11, 100\% of all participants showed a sense between proud to extremely proud toward the end result they've accomplished. In this respect, students who assembled the touchpad felt involved in the process of assembly. And this in terms will generate a positive atmosphere that allow the students to continue using the touchpads and be more creative in its usage. Moreover, students were showcasing their assembled touchpads to their friends and family members and this in term built a strong sense of belonging and attachment to the device. In fact, according to figure 13, $79 \%$ of participants showed a strong sense of attachment that could be translated into a more effective usage for the assembled touchpads in their future labs and projects. As a direct result of that, and according to figure 12, $77 \%$ of participants showed a strong willingness that they would use the touchpad in their future project and research.

In consequence to the above survey, the grade records of a group of undergraduate 12 students who took an animation course last year and weren't involved in the touchpad assembly were compiled against a group of 8 students who took the same course but were introduced to the touchpad assembly. The result showed that the final project that was practical based for the first group averaged on $81.3 \%$, whereas the second group who used the touchpad assembly as a focal point in their project averaged $84.2 \%$. This increase of marks in the practical part of the final project can be seen as a positive coloration between 


\section{Macrothink}

using the touchpad and getting better marks.

Below is a list of statistical figures that were compiled from the row data gathered during the survey:

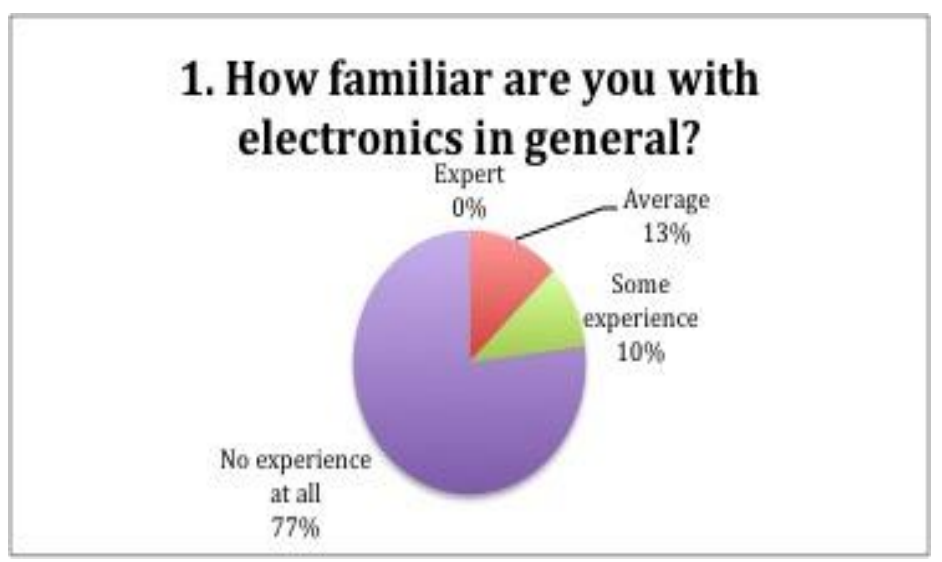

Figure 1. Students' familiarity with electronic devices in genearl

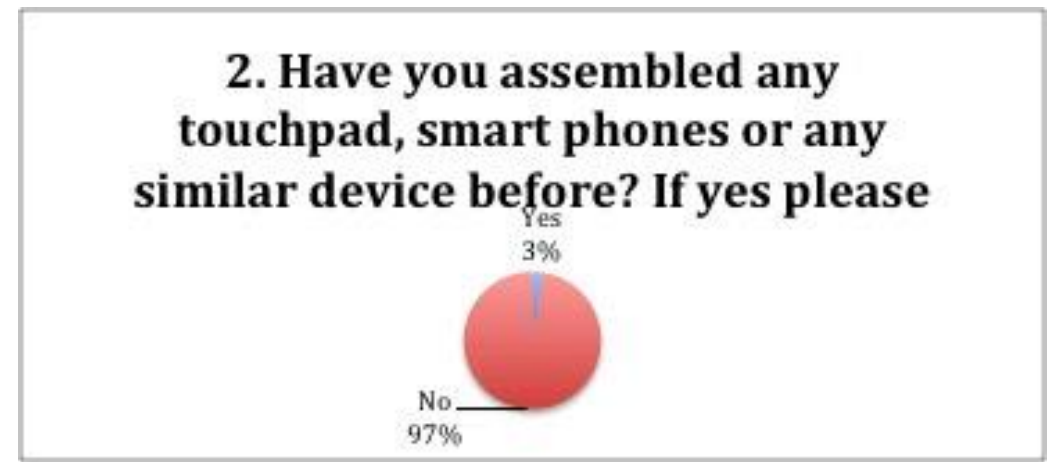

Figure 2. Previous experience in assembling touchpads or smart devices

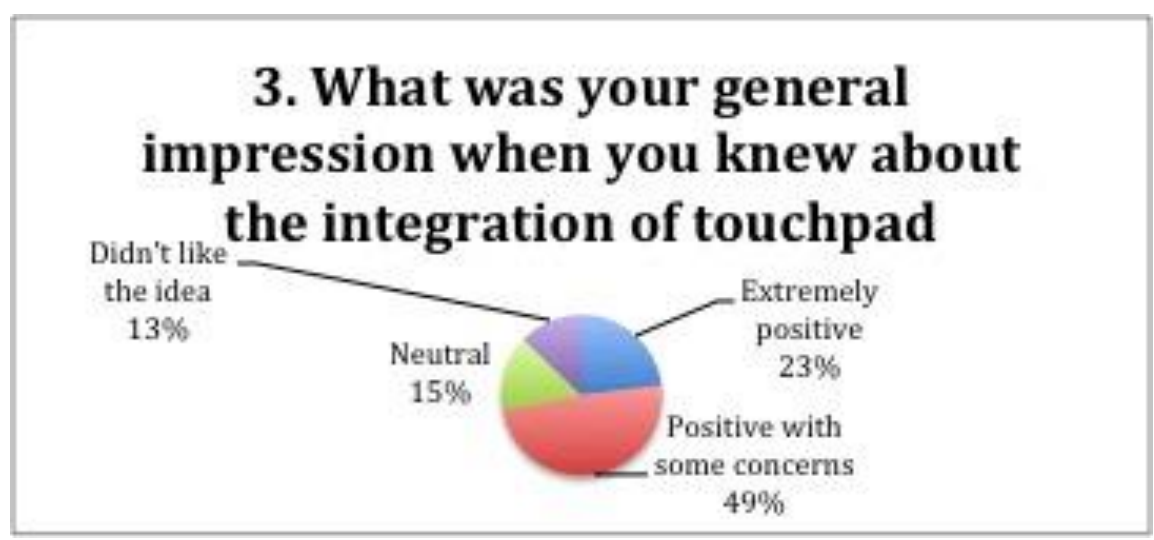

Figure 3. Students' impression on integrating the touchpad assembly in their course curriculum 


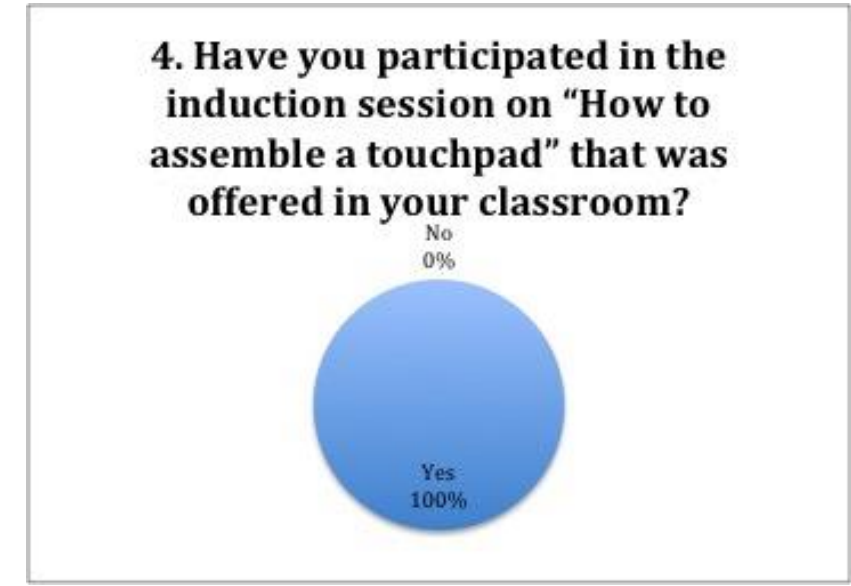

Figure 4. Percentage of students who actually participated in the touchpad assemblyinduction session

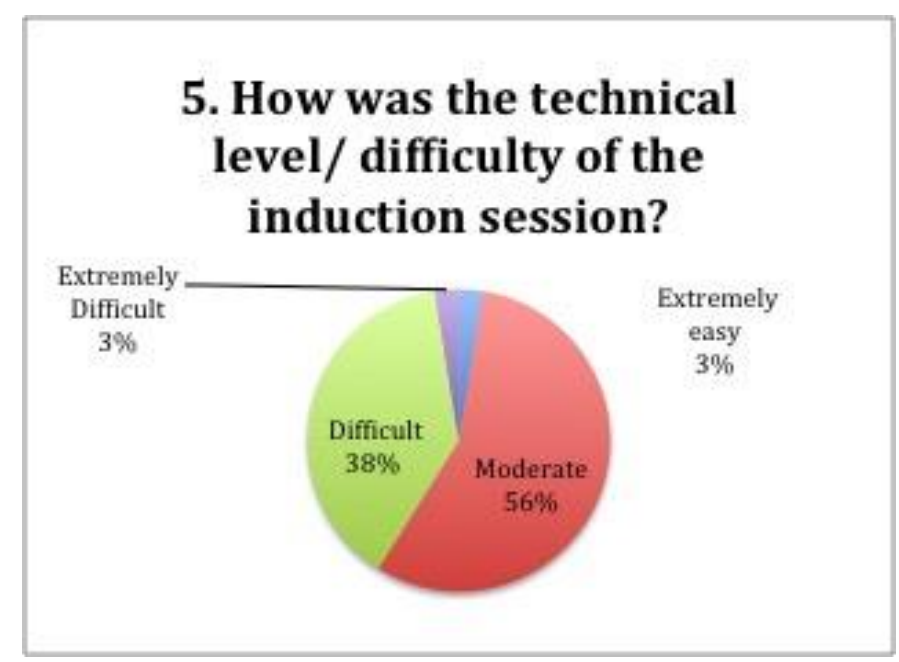

Figure 5. General question on the level of difficulty of the induction session

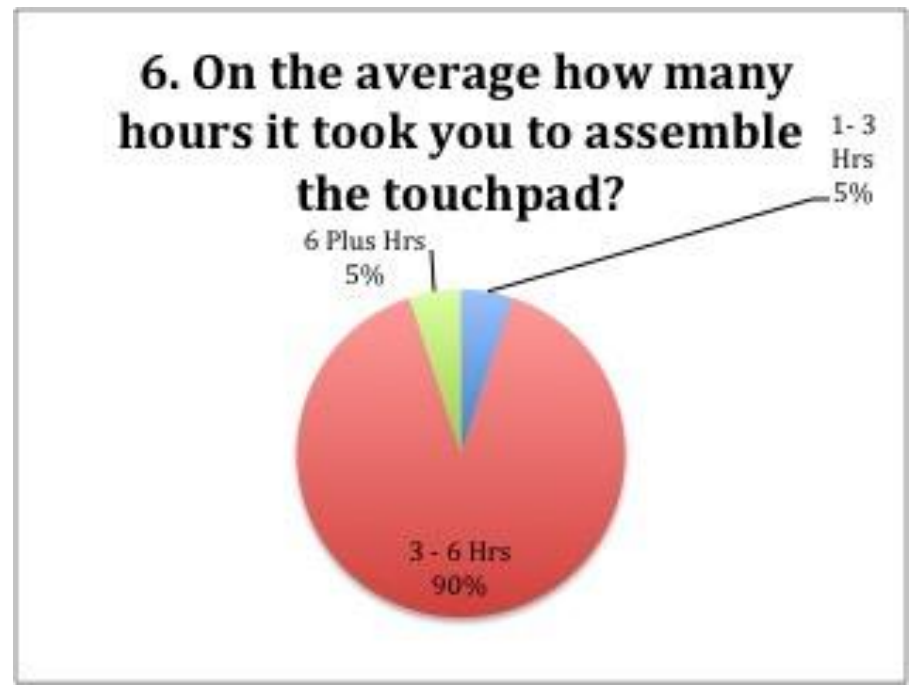

Figure 6. Average hours it took students to assemble their touchpad 


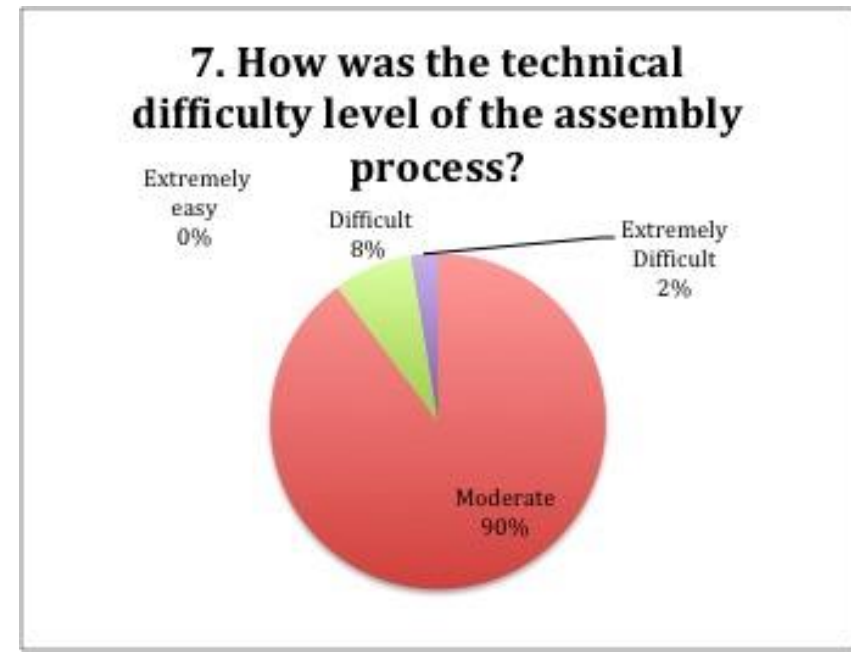

Figure 7. The level of difficulties of assembling the touchpad

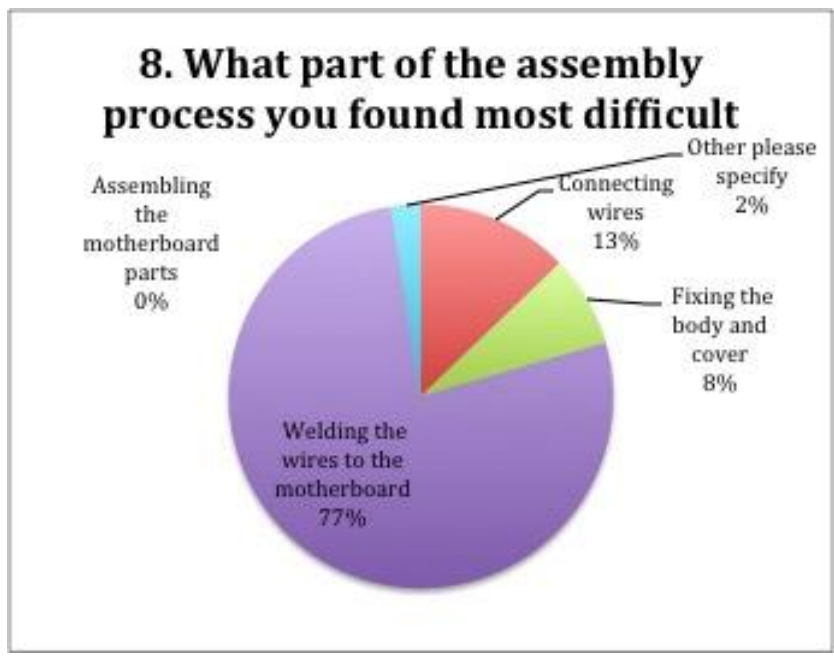

Figure 8. Identifying the most challenging part of assembling the new touchpad

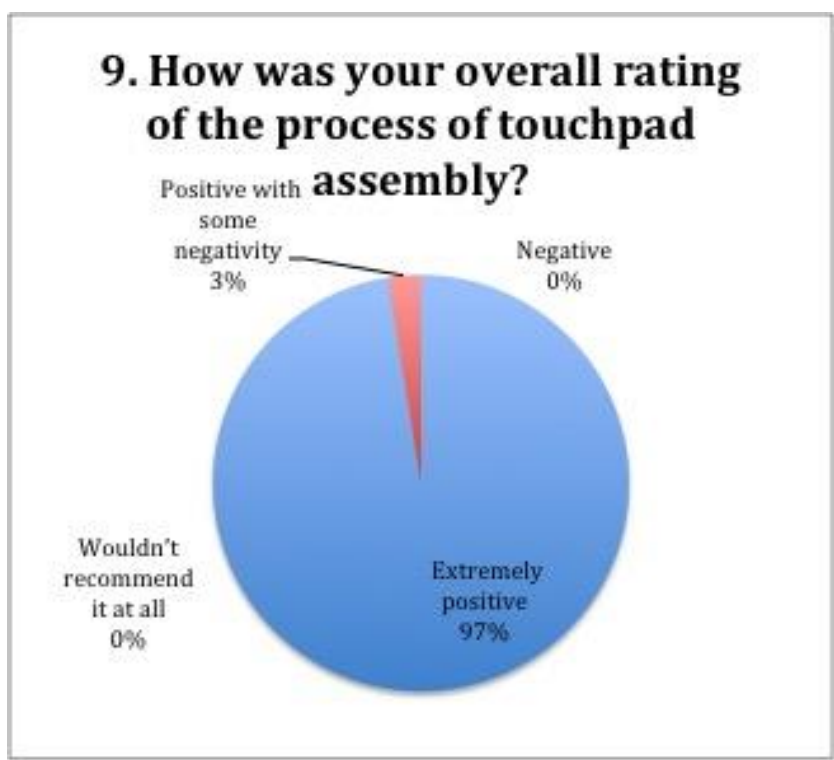

Figure 9. Students' general rating of the overall process of assembling the touchpads 


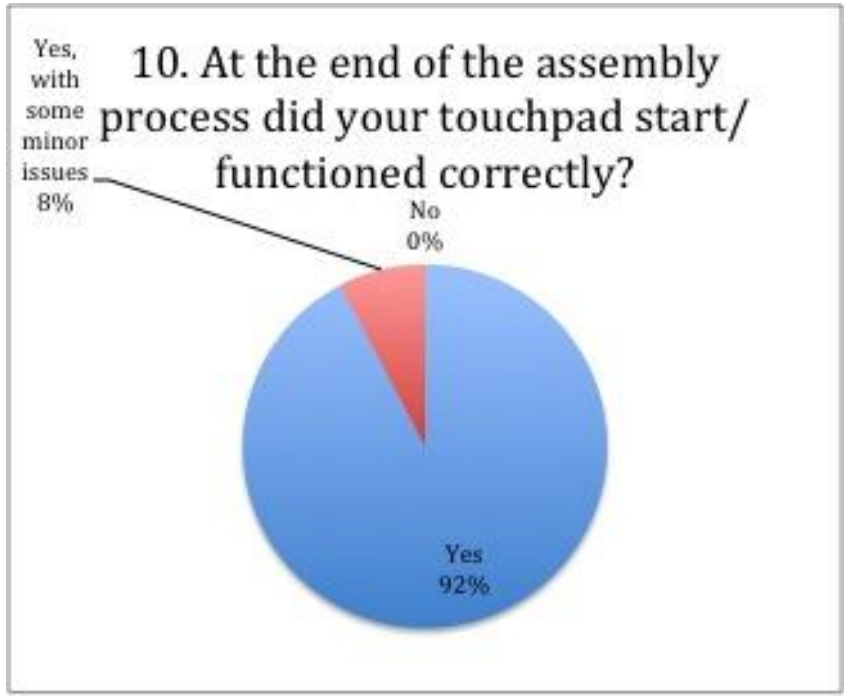

Figure 10. Level of touchpad successful assembly among students

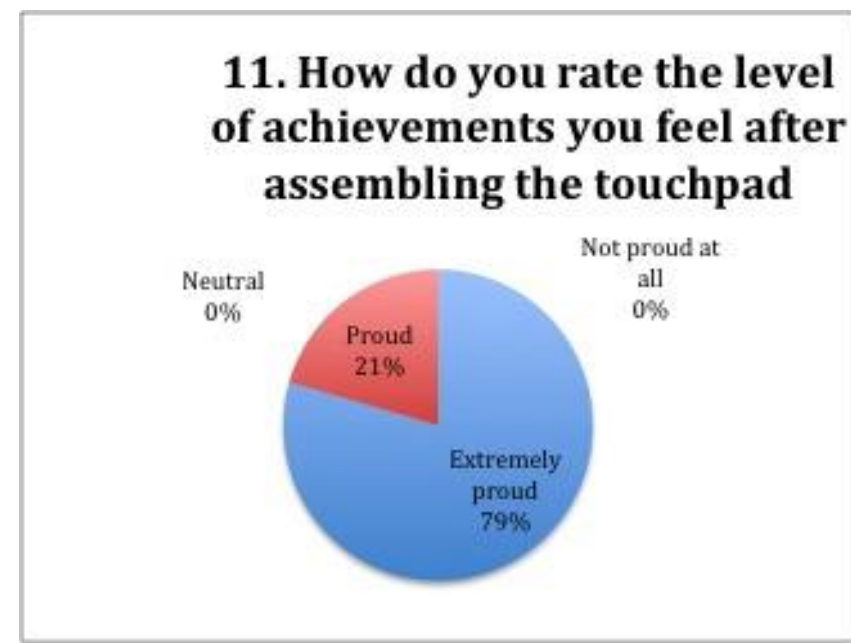

Figure 11. Level of students' satisfaction in correspondence to successfully assembling the touchpads

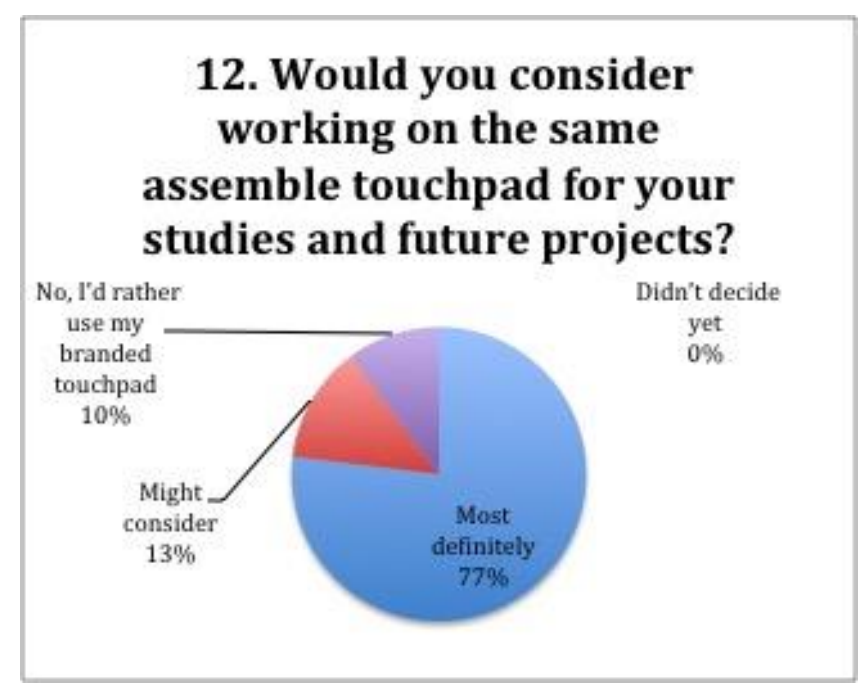

Figure 12. Students' willingness to use the newly assembled touchpad in their future studies 


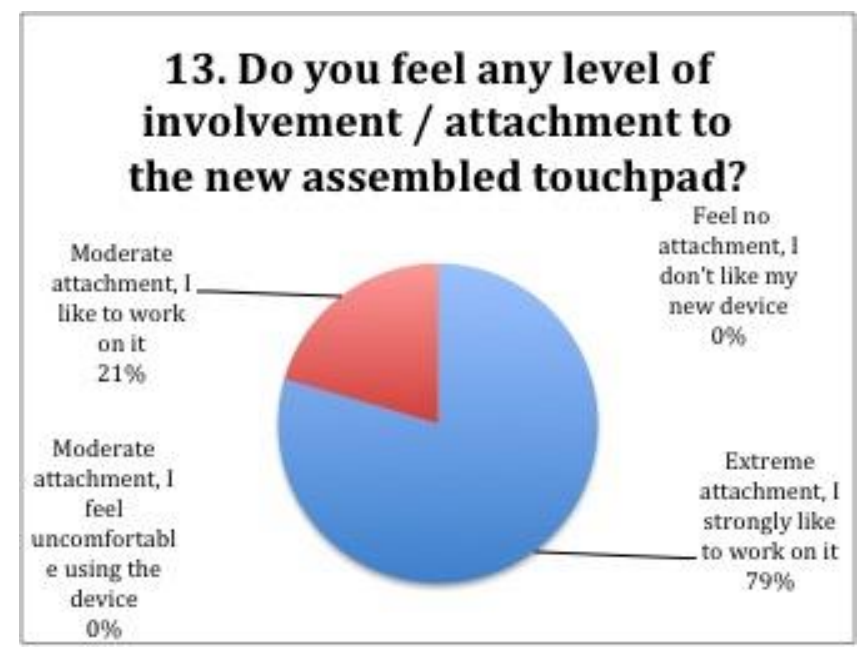

Figure 13. Level of attachments to the new assembled touchpad the students' experience

\section{Technical Information on the Touchpad Tablets:}

The HCT contacted a company in china under the name "Efortune" and had them delivered more than 1500 touchpads all in parts. The devices have the following specifications as shown in Table 1 below:

Table 1. Touchpad specifications

\begin{tabular}{|c|c|c|}
\hline No & Part name & Specifications \\
\hline 1 & Q88-PCBA M.B & Motherboard with BIOS loaded with Android OS \\
\hline 2 & Screen & $800 * 480,3.5$ thick, 60 pin /BOE screen \\
\hline 3 & Touch-Panel & High response Q8-TP touch panel \\
\hline 4 & Camera & T397 GC0308+GC0308 \\
\hline 5 & Battery & With capacity 3.7V/_mA/h \\
\hline 6 & Speaker & $14 * 20, \mathrm{~L}=100 \mathrm{MM}, 3.0 \mathrm{MM}$ thick \\
\hline 7 & Antenna & $\mathrm{L}=100 \mathrm{MM}$ \\
\hline 8 & Face Case & Main plastic case (white or black color) \\
\hline 9 & Back Housing & \\
\hline 10 & Bolt & KA1. $4 * 4$ head diameter 2.5, thick of head $0.5 \mathrm{~mm}$ \\
\hline 11 & Volume switch & According to housing specification \\
\hline 12 & Side switch & According to housing specification \\
\hline 13 & Speaker & 2415dedicated speaker / Silver \\
\hline 14 & Camera front lens / Camera Back lens & According to housing specification \\
\hline 15 & PCBA Insulation past & Q8 dedicated \\
\hline 16 & Black velvet tape & $\begin{array}{l}\text { 10MM(Wide); 70MM (Long); } \\
\text { 10MM(Wide); 40MM (Long); } \\
\text { 10MM(Wide); 30MM (Long); }\end{array}$ \\
\hline 17 & Double-faced adhesive tape & $\begin{array}{l}\text { 15MM (Wide); } \\
\text { 100MM(Long) }\end{array}$ \\
\hline 18 & Temperature resistant tape & 15MM (Wide); \\
\hline
\end{tabular}




\begin{tabular}{|l|l|l|}
\hline 19 & Sticky pads (8*8 MM and 1MM & Used for camera \\
& (Thick) & \\
\hline 20 & Masking tape & $10 \mathrm{MM}$ (Wide); \\
& & $120 \mathrm{MM}$ (Long) \\
\hline 21 & Blister inn Box & 7 inch special Blister box \\
\hline 22 & Charger & DC Head charger \\
\hline 23 & CPE Bag & Used to pack the touchpad tablet \\
\hline 24 & USD Line & 60cm Micro USB plug 5P, 6 line length 60cm \\
\hline 25 & OTG line & $\begin{array}{l}\text { Micro USB plug 5p, for A female head, } 4.5 \text { feet short } \\
\text { circuit }\end{array}$ \\
\hline
\end{tabular}

Assembled touchpad technical specifications and parts.

\subsection{Installation process / video demonstration:}

Below are list of instructions that are given to all students before they embark on their practical assembly practice:

1) Make sure you have a free space and you open the touchpad tablet parts and line them up all next to you

2) Wear an antistatic wrist pad and make sure you have a small star-head screwdriver and a soldering machine with enough 0.5 tin lead rosin core soldering iron wires.

3) Cover the battery with the temperature resistant tape so that you will protect it while you are welding the connections for the battery and touch panel into the motherboard.

4) Place the screen under the Face Case, Data cable should go below

5) Tape the screen to the Face Case using masking tape

6) Clip the Touch Panel to the body of the Face Case

7) Place heat insulation tape on the back of the motherboard

8) Fix the motherboard with the three star bolts on the back of the Face Case

9) Plug the camera data bus into the mother board

10) Apply three double sticky tapes on the battery and attach it to the back of the touch panel

11) Weld the wireless antenna card, speaker, touch panel and finally the battery to the motherboard each into its specified area.

12) Connect the Touch Panel and the screen data buses into the mother board

13) Tape the Camera with masking Tape and place the pad on top of it 
14) Secure and flatten down all wires, connections and data buses with black velvet tape.

15) Place the front/back camera lens in their designated location

16) Place the volume controller and ON/OFF Switch in their perspective location on the back cover

17) Plug the touchpad into the adapter and wait till the OS loads

18) If everything is working properly, secure the back cover into the touchpad and enjoy the new device.

For a visual step-by-step demonstration on the process of assembly, please visit the following video demonstration that I created to help students in their quest:

https://www.youtube.com/watch?v=JSkV498qSrw

\section{Touchpad Tablets Cost Benefit Study}

Giving the students the opportunity to build their own touchpads is proven not only effective in boosting students' academic achievements, but also on their financial status as well.

Previously students in the HCT had to buy their own branded touchpad devices such as iPad or Samsung and that would cost on the average around 500 US dollars. At this point the average assembled touchpad device cost the students around 30 US dollars and that is almost $6 \%$ of the price of the branded touchpad device. For detailed comparison between branded touchpads and the assembled one in terms of features and prices please take a look at table 2 below:

Table 2. Touchpads comparison

\begin{tabular}{|c|c|c|}
\hline Touchpad & Features & Cost \\
\hline iPad mini & $\begin{array}{l}\text {-16 GB Internal memory } \\
\text {-1GB RAM DDR3 } \\
\text {-Screen size }=7.9 \text { inches } \\
\text {-Max Resolution } 1536 * 2048 \\
\text {-Physical Dimension: } 200 * 134,7 * 7.5 \mathrm{~mm} \\
\text {-OS = iOS } 8.1 \\
\text {-CPU = Dual core } 1.3 \text { Ghz cyclone ARM V8-Band } \\
\text {-Dedicated Graphic adapter (Power VR G6430) } \\
\text { - 5 MB Front camera, } 1.2 \mathrm{MB} \text { Secondary } \\
\text { Wifi, GPS, Bluetooth, USB }\end{array}$ & $\$ 300$ \\
\hline Galaxy Tab 7.0 & $\begin{array}{l}\text {-16 GB Internal memory } \\
\text {-1GB RAM DDR3 } \\
\text {-Screen size = } 7 \text { inches } \\
\text {-Max Resolution } 1024 * 600 \\
\text {-Physical Dimension: } 193.65 * 122,37 * 9.96 \mathrm{~mm} \\
\text {-OS = Android 4.1.2 Jelly Bean }\end{array}$ & $\$ 105$ \\
\hline
\end{tabular}




\begin{tabular}{|c|c|}
\hline & $\begin{array}{l}\text {-CPU = Dual core 1.7 Ghz Dual Core } \\
\text { - No dedicated graphic adapter } \\
\text {-3MB Front camera, } 2 \mathrm{MB} \text { secondary camera } \\
\text {-Wifi, GPS, Bluetooth, USB }\end{array}$ \\
\hline Assembled Touchpad & $\begin{array}{l}\text {-16 GB Internal memory } \\
\text {-1GB RAM DDR3 } \\
\text {-Screen size }=7 \text { inches } \\
\text {-Max Resolution } 800 * 480 \\
\text {-Physical Dimension: } 180 * 120 * 5 \mathrm{~mm} \\
\text {-OS = Android 4.1.1 Jelly Bean } \\
\text {-CPU = 1.2 Ghz (configured according to order) } \\
\text {-No Dedicated Graphic adapter } \\
\text { - 2MB Front camera, } 1.2 \text { MB Secondary } \\
\text {-Wifi and USB available } \\
\text {-GPS, Bluetooth are Not available }\end{array}$ \\
\hline
\end{tabular}

Technical comparison among the most famous mini touchpads in the UAE.

\section{Conclusion}

Using the latest technologies to enhance the performance of higher education students is an essential task every educational institute must undertake. The type of technology varies from institute to another and from country to another. Here in the U.AE, the Higher Colleges of Technology is allowing its students to assemble their own touchpads and integrate this custom made technology into their projects and college work. This process proved to be extremely effective in terms of helping students actively improve their educational performance. In contrast to the branded off the shelve touchpads the students usually use temporarily and loose interest in, the assembled touchpads proved to have more sentimental value to the students and therefore are being used extensively. At the same time, the assembled touchpads are much more accessible for all the students in terms of price and technical specification. In fact these devices are perfectly aligned with most of students' academic projects and can be integrated in almost all aspects of student's education.

In summery, using the assembled touchpads in the HCT proved affordable and increased both students willingness to use technology in their education and their overall academic performance.

\section{References}

Saxena, S. (2013). Using Technology in Education: Does It Improve Anything?. The Edteh review News Site. Retrieved from http://edtechreview.in/news/681-technology-in-education

Moyle, K. (2010). Building Innovation: Learning with technologies. Australian council for educational research. Retrieved from http://research.acer.edu.au/aer/10

Baiyun C, \& Denoyelles, A. (2013). Exploring Students' Mobile Learning Practices in Higher Education. Educause Review online, 12, 1-2. 


\section{Copyright Disclaimer}

Copyright reserved by the author(s).

This article is an open-access article distributed under the terms and conditions of the Creative Commons Attribution license (http://creativecommons.org/licenses/by/3.0/). 